\title{
MODELLING SNOW SLAB RELEASE USING A TEMPERATURE-DEPENDENT VISCOELASTIC FINITE ELEMENT MODEL WITH WEAK LAYERS
}

\author{
MARTIN STOFFEL ${ }^{1}$ and PERRY BARTELT ${ }^{2}$ \\ ${ }^{1}$ Swiss Federal Institute for Snow and Avalanche Research, Flüestrasse 11, CH-7260 Davos Dorf, \\ Switzerland \\ E-mail: stoffel@ibk.baug.ethz.ch \\ ${ }^{2}$ Institute of Structural Engineering, ETH Zürich, CH-8093 Zürich, Switzerland \\ E-mail: perry.bartelt@wsl.ch
}

(Received 15 December 2002; Accepted 4 April 2003)

\begin{abstract}
A two-dimensional thermo-mechanical plane-strain finite element model for snow is presented. Snow is modeled as a two component porous medium consisting of a solid ice matrix and interstitial pore air. The ice and air phases are not always in thermal equilibrium. Therefore, heat transport is governed by two non-stationary energy conservation equations which are coupled by free convection heat exchanges at the interfacial ice-air boundary. The ice matrix deforms viscoelastically according to an experimentally-based temperature dependent constitutive law. Creep deformation rates are governed by a power law with a density dependent exponent $n$. The highly nonlinear character of the mechanical model is illustrated by simulating snowcovers with layers of variable height and density. Weak layer interfaces - believed to be the location of initiation of snow slab fracture - are modeled using special finite elements which transfer normal stresses but have little or no shear resistance. Stress and strain-rate concentrations at the boundaries of weak zones are calculated and compared with brittle fracture strain-rates.
\end{abstract}

Keywords: avalanche formation, porous continua, snow, viscoelasticity, weak layer

\section{Introduction}

The mechanics of snow slab release have been investigated by Bader et al. (1989) and Bader and Salm (1990). In these works, two-dimensional model calculations were performed to predict stress and strain-rate concentrations along super-weak interfaces, assumed to be located between two homogeneous snow layers. The snow layers were modelled as continua of constant mechanical properties. The steady-state creep response of the snowcover under self-weight was predicted. That is, creep velocities and strain-rates for snowcovers near fracture were determined. Transient effects, from temperature variations, or non-linear material effects, arising from the densification of the snow layers, were not included in the analysis. In addition, the weak interfaces had known length, thickness and mechanical properties.

The primary conclusion derived from the model calculations was that slab avalanches cannot be formed without super-weak layers. The self-weight of the 
snowpack alone is not enough to generate the strain or deformation rates required to fracture the homogeneous layers. They concluded that weak layers are a necessary condition for avalanche release. The idea of "super-weak" zones has taken hold in the popular avalanche literature (Munter, 1997). The result is also supported by field observations of avalanche release areas where the basal sliding surface of the slab is usually clearly defined.

The model calculations of Bader and Salm (1990), however, were based on several questionable assumptions. They assumed that the snowcover consisted of two high density snow layers, $\rho>400 \mathrm{kgm}^{-3}$. The viscosity of the snow layers was based on the triaxial tests of Salm (1971), $\eta=5 \times 10^{10}$ Pas. Both the high values of density and viscosity are particularly advantageous for avalanche release: the high density increases the self-weight of the upper layer, and the high viscosity increases the stiffness of the upper layer. Thus, the applied load causes little deformation and transfers the stress directly to the weak layer. Zones of high strain-rate concentrations $\dot{\epsilon} \approx 10^{-3} \mathrm{~s}^{-1}$ at the ends of the layer are readily formed. New snow densities and viscosities of the order $\rho \approx 100 \mathrm{kgm}^{-3}$ and viscosities near $\eta \approx 1 \times 10^{9}$ Pas would be more appropriate (Bartelt and von Moos, 2000).

The goal of this work is to advance the initial investigations of Bader and Salm (1990). Although this earlier work was incomplete and based on unrealistic assumptions, it was a first attempt to relate the constitutive properties of snow to snowcover stability. It did propose a consistent theory taking into account the viscoelastic properties of snow and the layered structure of the snowpack.

Several recent developments make advances possible. First, the temperature dependent viscoelastic properties of snow have now been quantified over a wide range of densities (von Moos et al., 2003). The newly formulated viscosity laws (Scapozza and Bartelt, 2003a) vary significantly from the constant viscosity assumed by Bader and Salm (1990), but are only valid for fine grained snow of rounded grains. Secondly, numerical methods are now available to treat layer discontinuities. Although the constitutive laws for weak layers are presently unknown, layers of little or no shear strength can be assumed. This approach differs from the earlier investigations, which treated the weak layers as a thin isotropic continuum layer. Finally, the temperature dependence of snow (Scapozza and Bartelt, 2003b), in the form of an apparent activation energy, $Q$, has been determined. The influence of temperature variations on the deformation rates can be predicted.

The paper proceeds as follows. In the next section, the viscoelastic properties of snow are reviewed. Then, the thermal non-equilibrium treatment of snow is discussed. Non-equilibrium refers to the fact that the temperature in the pore space and ice lattice may differ. Heat transfer is governed by the thermal conductivities of each phase and natural convection between the air and ice. Two non-steady energy conservation equations are required. Afterwards the fully implicit thermomechanical finite element model with weak interfaces and periodic boundary conditions is formulated. Deformation rates of snowpacks on slopes of constant angle, different weak layer length and variable temperature are then calculated. 
The present work attempts to resolve the question whether weak layers (or other perturbations) are a sufficient condition to achieve brittle fracture deformation rates. This does not mean that weak layers are the unique condition for an avalanche to occur. The concomitant breakage of a set of intergranular bonds, for example, can also be a proper mechanism for an avalanche release.

\section{The Mechanical Deformation of Snow}

It has been shown that, under applied axial loading, snow will deform viscoelastically (Voytkovskiy, 1977). The total axial strain $\epsilon$ is the sum of the elastic and viscous parts:

$$
\epsilon=\epsilon_{e}+\epsilon_{v} .
$$

In general, the elastic strains are small in comparison to the total viscous strains, $\epsilon_{e} \ll \epsilon_{v}$, especially over the course of several days, or weeks. The total volumetric strains of new snow can be over $200 \%$ within a few days, depending on temperature. Almost all the strain is viscous and irreversible. However, instantaneous irreversible strains, for example from an external loading like a skier, are not taken into account by this model.

Triaxial tests on snow (von Moos et al., 2003) reveal that the elastic strain can be further divided into two parts, an initial elastic and time-dependent and reversible strain (inelastic strain):

$$
\epsilon_{e}=\epsilon_{0}+\epsilon_{a} .
$$

Young's modulus $E$ relates the state of stress to strain $\epsilon_{0}$; values for $E$ are provided in Figure 1 as a function of density. It has been found that $E$ is for the most part strain-rate and temperature independent. Lower density snow, however, exhibits significant inelastic straining in comparison with higher density snow (Scapozza and Bartelt, 2003a).

For the plane-strain problems studied in the following the elasticity matrix, $\mathbf{E}$ is given by:

$$
\mathbf{E}=\frac{\mathrm{E}(1-v)}{(1+v)(1-2 v)}\left[\begin{array}{ccc}
1 & \frac{v}{1-v} & 0 \\
\frac{v}{1-v} & 1 & 0 \\
0 & 0 & \frac{1-2 v}{2(1-v)}
\end{array}\right]
$$

where $v$ is Poisson's number. As usual, the elasticity matrix relates the plane-strain components $\epsilon=\left(\epsilon_{x}, \epsilon_{y}, \gamma_{x y}\right)^{T}$ to the stress components $\sigma=\left(\sigma_{x}, \sigma_{y}, \tau_{x y}\right)^{T}$. Poisson's number is set to zero since triaxial tests show that for snow the deformation 


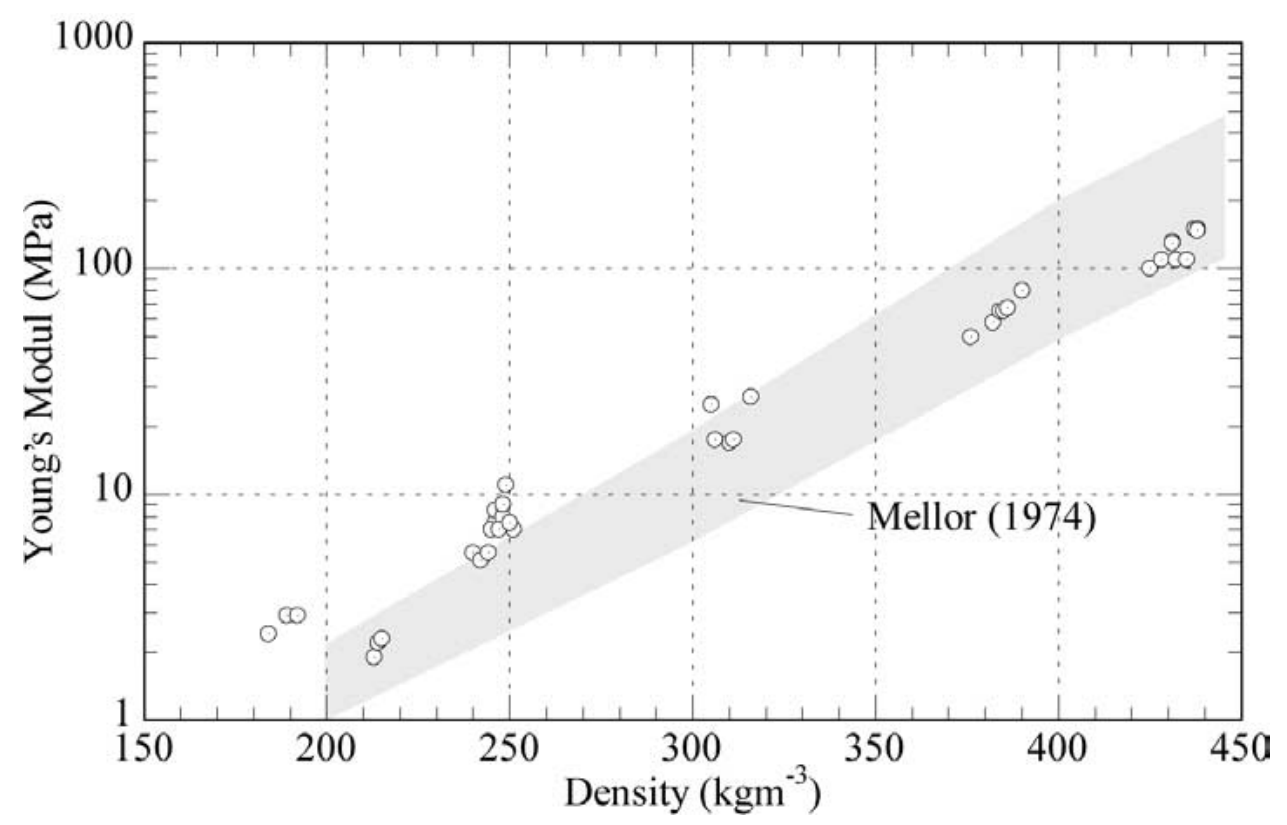

Figure 1. Young's modulus for snow based on the experiments of von Moos et al. (2003). Values are in good agreement with $E$ values found in Mellor (1974) or Voytkovskiy (1977).

directions are independent of each other until a critical strain is reached (Scapozza and Bartelt, 2003b).

Viscous straining in the granular ice matrix is due to different deformation mechanisms occurring in the ice crystals or ice crystal boundaries (Scapozza and Bartelt, 2003a). For the natural strain-rates and stress levels considered (no skier or other artificial loadings), when extensive bond breakage does not occur, the two rate controlling creep mechanisms are evidently dislocation creep and grain boundary sliding (Petrenko and Whitworth, 1999). Hence, as for polycrystalline ice, the viscous deformation of snow can be modelled with a power law relation:

$$
\dot{\epsilon}_{v}=A_{0} e^{-\frac{Q}{R T}} \sigma_{y}^{n}=A \sigma_{y}^{n}
$$

where $\dot{\epsilon}_{v}$ is the viscous strain-rate in $\mathrm{s}^{-1}, A_{0}$ is a density dependent material parameter (in $\mathrm{kPa}^{-n} \mathrm{~s}^{-1}$ ), $Q$ is the apparent activation energy (in $\mathrm{kJmol}^{-1}$ ), $R$ is the gas constant $\left(\mathrm{kJmol}^{-1} \mathrm{~K}^{-1}\right), T$ is the temperature of ice $(\mathrm{K}), \sigma_{y}$ is the yield stress (in $\mathrm{Pa}$ ) and $n$ is a dimensionless exponent. This relationship is found from extensive triaxial testing for different densities, strain-rates and temperatures (Scapozza and Bartelt, 2003b).

Unlike ice, however, the model parameters $Q$ and $n$ vary with snow density (Figure 2). At densities of $\rho \approx 400 \mathrm{kgm}^{-3}$ parameters similar to those for polycrystalline ice can be used in the material model, say $n=3.0$ and $A=$ $10^{-25}\left(\mathrm{~Pa}^{-n} \mathrm{~s}^{-1}\right)$. 

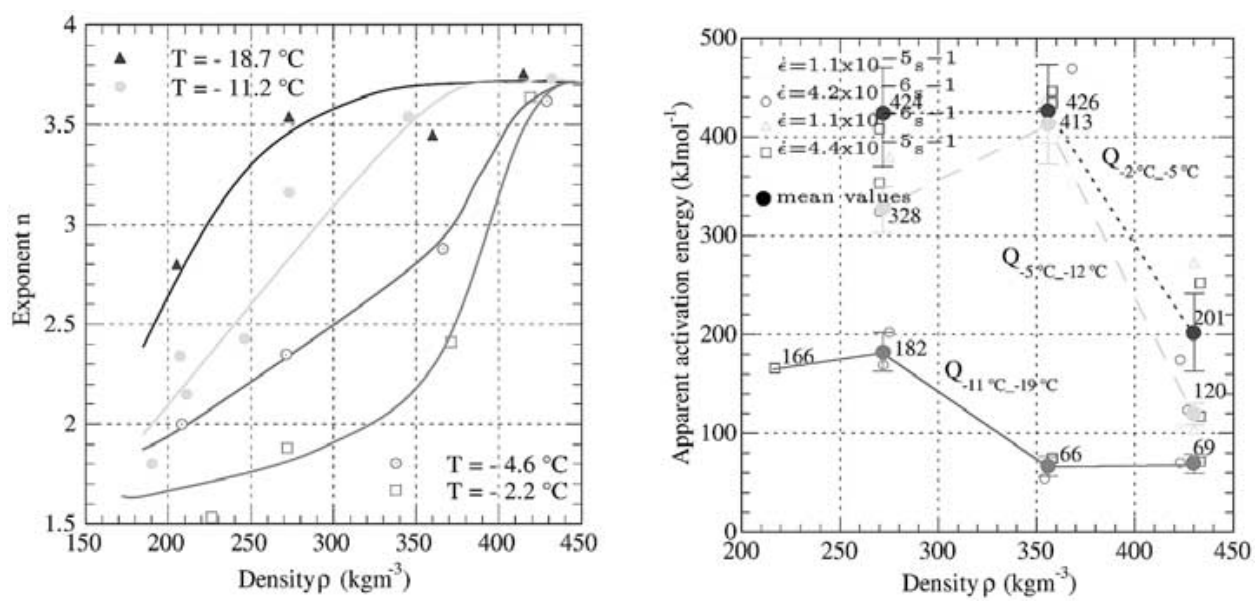

Figure 2. Left: Temperature and density dependence of the exponent $n$ for strain-rates ranging between $\dot{\epsilon}=1.1 \times 10^{-6} \mathrm{~s}^{-1}$ and $\dot{\epsilon}=4.4 \times 10^{-5} \mathrm{~s}^{-1}$. From Scapozza and Bartelt (2003b). Right: Temperature and density dependence of the apparent activation energy $Q$ for different strain-rates.

For the numerical finite element implementation, the viscosity $\eta$ must be defined:

$$
\sigma=\eta \dot{\epsilon}_{v} .
$$

Thus, for the power law formulation, the viscosity of snow is:

$$
\eta=\frac{1}{A \sigma_{I I}^{n-1}}
$$

where $\sigma_{I I}$ is the second stress invariant defined as $\sqrt{\frac{1}{2}\left(\sigma_{x}^{2}+\sigma_{y}^{2}\right)+\tau_{x y}^{2}}$.

Since the parameters $n$ and $A$ are density, temperature and strain-rate dependent, the viscosity is highly nonlinear, requiring a numerical solution for the problems of interest. Finally, the viscosity matrix $\mathbf{V}$ is given by:



This matrix relates viscous strain-rate components $\dot{\epsilon}_{\mathbf{v}}=\left(\dot{\epsilon}_{v x}, \dot{\epsilon}_{v y}, \dot{\gamma}_{v x y}\right)^{T}$ to the stress components $\sigma=\left(\sigma_{x}, \sigma_{y}, \tau_{x y}\right)^{T}$. The parameter $m$ is the viscous analogue to Poisson's number, which we set to a large number, uncoupling the $x$ and $y$ directions. This relation was also used by Bader and Salm (1990) with $m$ values of 5 . 


\section{Non-equilibrium Heat Transfer}

The temperature state in the two-dimensional snowcover (coordinates $x$ and $y$ ) is governed by two non-stationary heat energy conservation equations:

$$
\begin{aligned}
& \theta_{a} \rho_{a} c_{a}\left(\frac{\partial T_{a}}{\partial t}+\mathbf{u}_{\mathbf{a}} \cdot \nabla \mathbf{T}_{\mathbf{a}}\right)-\theta_{a} k_{a} \nabla^{2} T_{a}=h_{a}\left(T_{i}-T_{a}\right) \\
& \theta_{i} \rho_{i} c_{i} \frac{\partial T_{i}}{\partial t}-k_{i} \nabla^{2} T_{i}=h_{a}\left(T_{a}-T_{i}\right)+L \dot{m}_{a \rightarrow i} .
\end{aligned}
$$

The first equation governs the heat transfer in the interstitial air space (temperature $T_{a}$, volumetric content $\theta_{a}$ ). It includes an advective term, where $\mathbf{u}_{\mathbf{a}}$ is the vector of interstitial air velocities, which is assumed to be in the creeping flow regime, $R e<10$. The second equation governs the heat transfer in the ice matrix (temperature $T_{i}$, volumetric content $\theta_{i}$ ). The thermal conductivities in the air and ice phases are given by $k_{a}$ and $k_{i}$, respectively. For $k_{a}$ the conductivity of air is used, $k_{a}=0.026 \mathrm{Wm}^{-1} \mathrm{~K}^{-1}$. For $k_{i}$ the microstructural conductivity model of Adams and Sato (1993) is employed, which relates grain and bond size to conductivity. The specific heats of the air and ice phases are $c_{a}=1000 \mathrm{~J} \mathrm{~kg}^{-1} \mathrm{~K}^{-1}$ and $c_{i}=$ $2100 \mathrm{~J} \mathrm{~kg}^{-1} \mathrm{~K}^{-1}$. Note that the thermal diffusivities of air and ice differ $\left(\alpha_{a}=2.6\right.$ $\times 10^{-5} \mathrm{~m}^{2} \mathrm{~s}^{-1}$ and $\alpha_{i}=1.1 \times 10^{-6} \mathrm{~m}^{2} \mathrm{~s}^{-1}$ ) by a factor of 20 . Thus, an important mode of heat transfer is the natural convection occurring at the interfacial air-ice boundary, which is a function of the temperature difference between the two phases and the convective heat transfer coefficient, $h_{a}$ (Kaviany, 1995). Sublimation and deposition of water vapour, (mass rate, $\dot{m}_{a \rightarrow i}$ ) from or to the ice lattice can also be accounted for; however, the influence of these effects is not included in the present analysis.

Boundary conditions at the lower $(y=0)$ and upper surfaces of the snowpack $(y=h)$ are specified:

$$
T_{i}(x, 0, t)=T_{a}(x, 0, t)=T_{0}(t)
$$

and

$$
T_{i}(x, h, t)=T_{a}(x, h, t)=T_{h}(t) .
$$

It is also possible to prescribe only the air temperature $T_{a}$ and let the convective heat exchange between the ice and air determine the ice temperature $T_{i}$. 


\section{Finite Element Model}

A two-dimensional finite element method is employed to solve the two nonstationary heat transfer equations. A fully implicit time-integration scheme is employed; simple four node quadrilateral elements are used for the spatial discretization. This is a standard technique; for more information see Reddy and Garling (1994). This procedure provides the ice and air temperature for all times and points of interest, $T_{i}(x, y, t)$ and $T_{a}(x, y, t)$, within the model domain. Note that the thermal conductivities are a function of the volumetric ice and air contents and thus are changing with mechanical deformation. Changes in snow microstructure, which would also influence the thermal conductivity, are not considered since the calculation times are on the order of 24 to 48 hours (not weeks or months).

The viscoelastic solution requires more attention. The governing differential equation for the mechanical deformation is:

$$
\nabla \cdot \sigma\left(\mathbf{T}_{\mathbf{i}}, \mathbf{u}_{\mathbf{i}}\right)-\mathbf{f}=\mathbf{0}
$$

where $\mathbf{f}$ are the applied body forces; in our case, this is the self-weight of the snowpack. The vector $\mathbf{u}_{\mathbf{i}}$ represents the deformation of the ice-matrix. The finite element discretization of this equation leads to a system of algebraic equations, expressed in incremental form as:

$$
\mathbf{K}_{\mathbf{t}} \Delta \mathbf{u}=\Delta \mathbf{f}_{\mathrm{g}}+\Delta \mathbf{f}_{\mathrm{v}}
$$

where $\mathbf{K}_{\mathbf{t}}$ is the tangent stiffness matrix, $\Delta \mathbf{u}$ is the increment in displacement, $\Delta \mathbf{f}_{\mathbf{g}}$ is the increment in body forces (self weight) and $\boldsymbol{\Delta} \mathbf{f}_{\mathbf{v}}$ is the increment of creep "forces" from time $t_{0}$ to $t_{1}$. The nodal vector $\Delta \mathbf{f}_{\mathbf{v}}$ is found by evaluating the element integral:

$$
\Delta \mathbf{f}_{\mathbf{v}}^{e}=\int_{A} B E \dot{\epsilon}_{v} \Delta t d A
$$

for all elements. (B is the finite element matrix relating nodal displacements to strains and $A$ is the element area.) The viscous creep strains are found from Equation (4) at each time $t$. Note that since the temperature and density change over time, the vector $\Delta \mathbf{f}_{\mathbf{v}}$ must be recalculated at each time step.

An initial static solution is calculated to start the time integration scheme which is a simple explicit Euler scheme. The time step, however, is adaptive using a maximum strain- change criterion in deciding the time step. The same finite element discretization is used for the mechanical solution as for the heat transfer calculation.

At the beginning of the finite element solution, the temperature distribution in the snowcover is known. It is further assumed that the air and ice phases are in thermal equilibrium,

$$
T_{a}(x, y, 0)=T_{i}(x, y, 0)=T_{0}(x, y) .
$$


The initial stress state $\sigma(x, y, 0)$ is determined by finding the elastic solution.

After the initialization phase, the time integration scheme is started. At every time $t$ the temperature distribution in the snowcover is found, for both the ice and air phases. Once the temperature in the ice phase is known, the creep displacements are calculated. This procedure is repeated until the desired calculation time is reached.

\section{Weak Interface}

Based on the work of Beer (1985) and Day and Potts (1994), the standard isoparametric element formulation was modified to model a zero thickness weak interface. The forces orthogonal to the weak layer interface in the local $n$-direction are transported directly to the surrounding layers. The transfer of shear forces in the local $s$-direction is governed by different laws such that relative shear motions can occur between the adjacent elements. In Figure 3 a weak interface element is shown. The pseudo elasticity matrix $\mathbf{E}_{\text {weak }}$ for a weak element is given by:

$$
\mathbf{E}_{\text {weak }}=\left[\begin{array}{cc}
\mathrm{E}_{\mathrm{s}} & 0 \\
0 & \mathrm{E}_{\mathrm{n}}
\end{array}\right]
$$

where $E_{s}$ is set to 0 , such that no resistance in the x-direction is present $\left(u_{s-t o p} \neq u_{s-b o t t o m}\right) . E_{n}$ is set to a large value, so that no relative displacement in $n$-direction can exist (i.e., $v_{n-t o p}-v_{n-t o p}=0$ ), this guarantees, that the element's height remains zero. Since the weak interface element has no volume, there are no volumetric effects (dilatancy) in the $\mathbf{E}_{\text {weak }}$ matrix. Although non-zero values for $E_{s}$ are theoretically possible, there is little experimental data available to justify a particular value; for this reason $E_{s}=0$ was chosen.

\section{Examples}

In the first example, the influence of weak layer length $a$ on the increase of maximum second strain-rate invariants is investigated. The snow density $\rho_{1}$ and temperature $T_{1}$ of the snow layer above the weak layer was also varied. Figure 4 depicts the model domain, a two layer snow pack on a $\phi=35^{\circ}$ slope. The periodic boundary conditions were introduced to model an infinitely long slope. The total length of the snowcover was chosen to be $50 \mathrm{~m}$, much longer than the maximum weak layer length of $a=20 \mathrm{~m}$.

In the first simulation the density of the top layer varied between $\rho_{1}=180$ to $300 \mathrm{kgm}^{-3}$ in steps of $20 \mathrm{kgm}^{-3}$. The weak layer length was chosen to be $a=12 \mathrm{~m}$. The maximum second strain-rate invariants as a function of density are presented in Table I. 


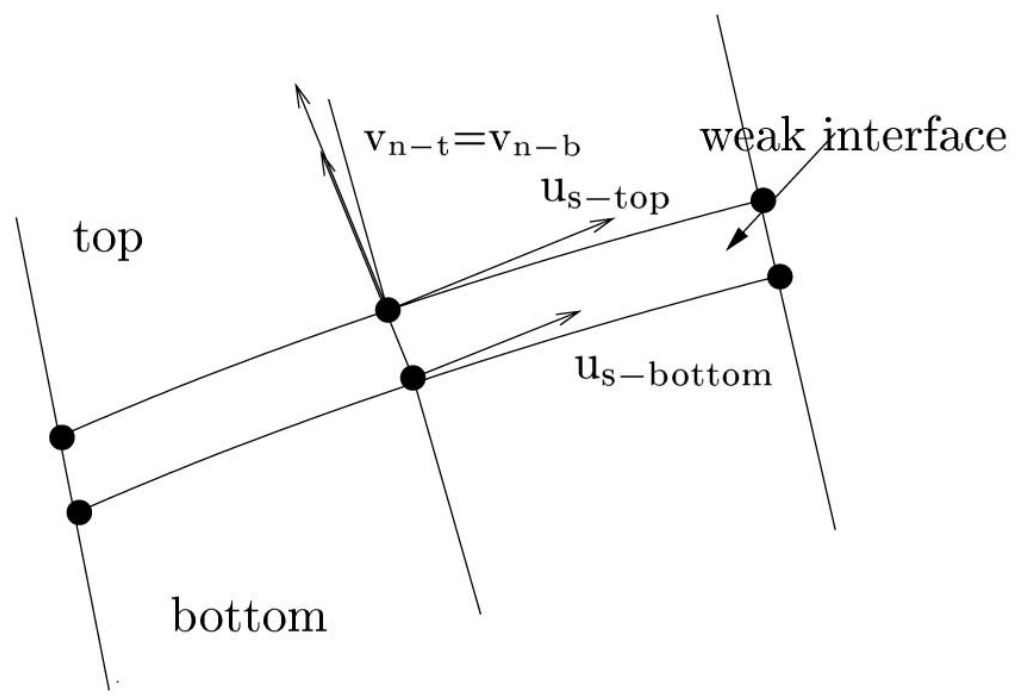

Figure 3. Definition of the "weak layer" element showing the deformation directions.

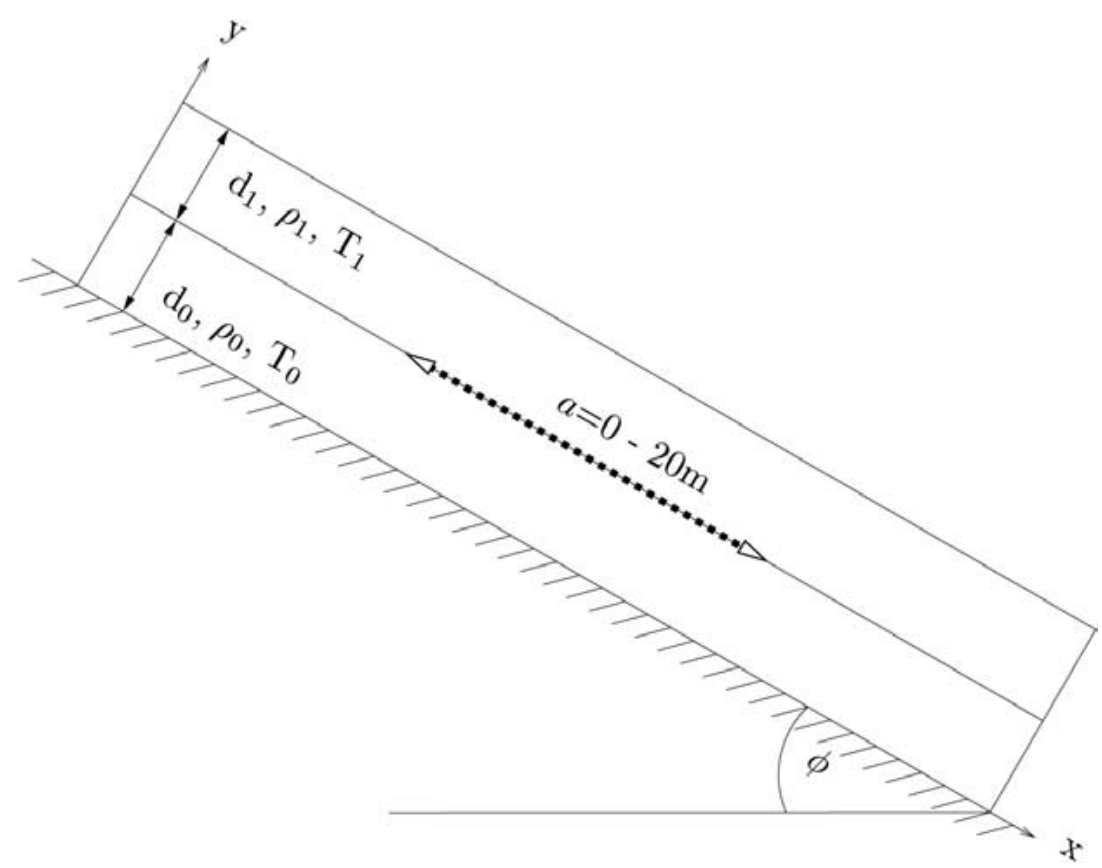

Figure 4. The influence of a temperature rise is investigated on snowcover depicted above. Constant slope at $\phi=35^{\circ}$ with a length of $50 \mathrm{~m}, \mathrm{~d}_{0}=\mathrm{d}_{1}=1 \mathrm{~m}, \rho_{0}=350 \mathrm{kgm}^{-3}$ and $\mathrm{T}_{0}=0{ }^{\circ} \mathrm{C}$. 


\section{TABLE I}

Second strain-rate $\dot{\epsilon}_{I I}$ invariant for top layer densities of $\rho_{1}=$ $180 \mathrm{kgm}^{-3}$ to $300 \mathrm{kgm}^{-3}$ at $\mathrm{T}_{1}=-6{ }^{\circ} \mathrm{C}$ with a weak layer length of $a=12 \mathrm{~m}$.

\begin{tabular}{ll}
\hline$\rho_{1}\left(\mathrm{kgm}^{-3}\right)$ & $\dot{\epsilon}_{I I}\left(\mathrm{~s}^{-1}\right)$ \\
\hline 180 & 0.00055465 \\
200 & $3.72822 \mathrm{e}-05$ \\
220 & $4.14770 \mathrm{e}-06$ \\
240 & $7.36637 \mathrm{e}-07$ \\
260 & $1.99843 \mathrm{e}-07$ \\
280 & $7.84886 \mathrm{e}-08$ \\
300 & $4.19101 \mathrm{e}-08$ \\
\hline
\end{tabular}

The results show that the calculated second strain-rate invariants approach the brittle fracture strain-rate $\dot{\epsilon}_{b}>10^{-4} \mathrm{~s}^{-1}$ as the density decreases.

In the next series of simulations, the weak layer length varied between $a=$ $0 \mathrm{~m}$ to $20 \mathrm{~m}$. The density of the top layer remained constant $\rho_{1}=180 \mathrm{kgm}^{-3}$ at a temperature of $\mathrm{T}_{1}=-6{ }^{\circ} \mathrm{C}$. The maximum second strain-rate invariants $\dot{\epsilon}_{I I}$ along the weak layer are depicted in Figure 5. The results show once more that the calculated strain-rates are greater than brittle fracture strain-rates for weak layer lengths $a>10 \mathrm{~m}$.

In the last series of simulations for this example the temperature of the upper layer varied from $\mathrm{T}_{1}=-12^{\circ} \mathrm{C}$ to $-2{ }^{\circ} \mathrm{C}$. For each temperature a time varying creep calculation was performed. The results of the different simulations are presented in Figure 6. Note that the strain-rates outside the weak layer differ, and the highest strain-rate occurs for $\mathrm{T} \approx-5{ }^{\circ} \mathrm{C}$. Thus, contrary to expectation, the strain-rate did not continously increase with increasing temperature. In general the results are in agreement with the conclusions of Bader and Salm (1990); however, a more realistic snow cover, with experimentally based viscosities, was used in these simulations.

In order to investigate this phenomenon still further, in the next example problem, the influence of a varying temperature rise on the creep strain-rates was investigated. A temperature rise of $\Delta T=10$ is applied to a $2 \mathrm{~m}$ high snowpack on a $\phi=35^{\circ}$ slope (to both the air and ice phases). The snowpack consists of two $1 \mathrm{~m}$ high homogeneous layers of $\rho_{1}=350 \mathrm{kgm}^{-3}$ and $\rho_{2}>180 \mathrm{kgm}^{-3}$. A $a=10 \mathrm{~m}$ long weak layer exists between the two layers (see Figure 4). The temperature rise is applied over different time intervals, $\Delta t=2 \mathrm{~h}, 6 \mathrm{~h}$ and 10h, starting after 6 hours with a constant temperature $T_{1}=-12{ }^{\circ} \mathrm{C}$.

Figure 7 shows the second strain-rate invariants at the upper end of the weak layer. The larger the temporal gradient in temperature, $\dot{T}_{i}$, the higher the maximum 


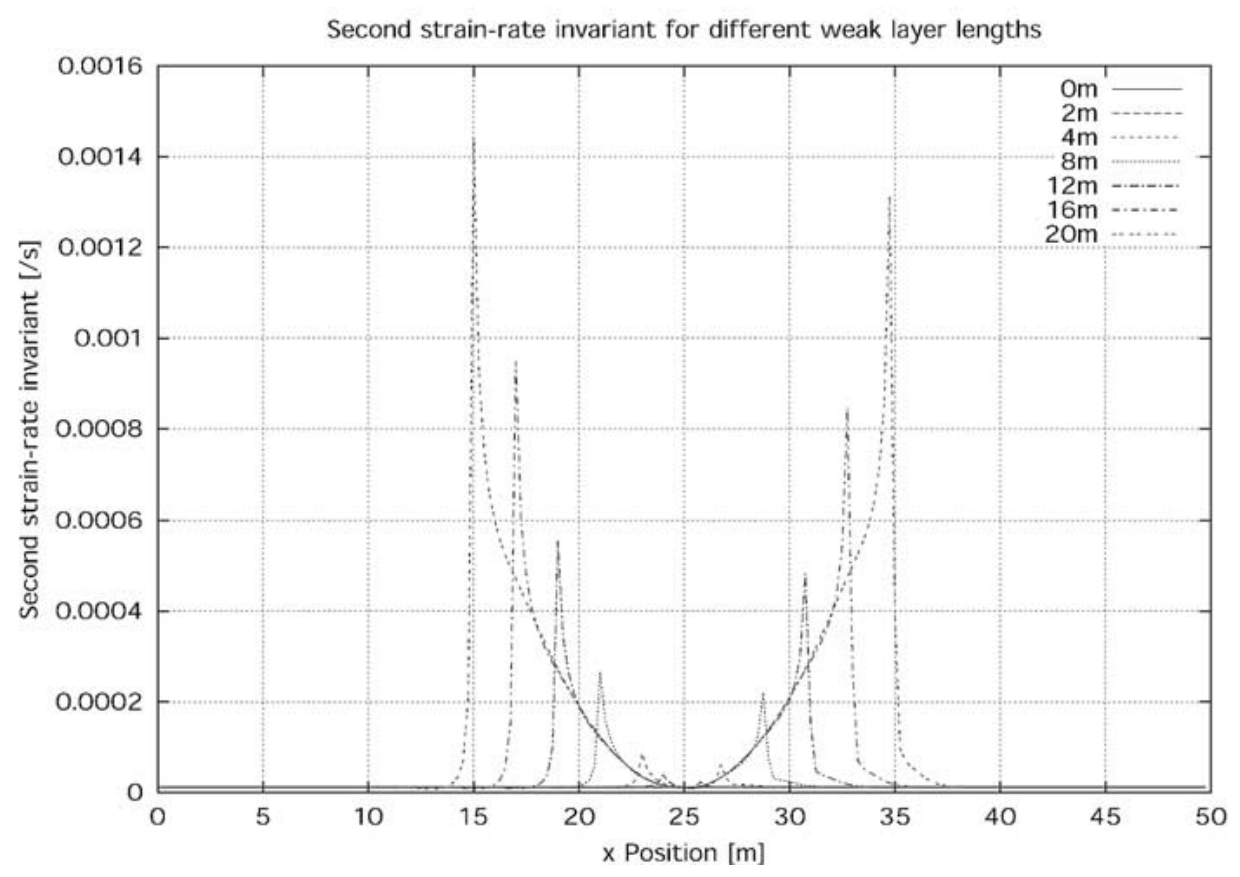

Figure 5. Second strain-rate invariant $\dot{\epsilon}_{I I}$ for different weak layer lengths from $a=0$ to $20 \mathrm{~m}$ with a constant upper layer density of $\rho_{1}=180 \mathrm{kgm}^{-3}$ at $\mathrm{T}_{1}=-6^{\circ} \mathrm{C}$.

strain-rate. Defining the brittle fracture strain-rates to be of the order $\dot{\epsilon}_{b}>10^{4} \mathrm{~s}^{-1}$, the snow is approaching a brittle fracture regime.

\section{Conclusions}

Based on the simulation results, we draw the following conclusions concerning snow avalanche formation:

- The initial results of Bader et al. (1988) and Bader and Salm (1990) could be substantiated, however, with realistic snowcovers and mechanical properties. Without perturbations (weak layers, discontinuities, bumps) it is impossible to obtain brittle strain-rate concentrations of $\dot{\epsilon}_{b}>10^{4} \mathrm{~s}^{-1}$. The larger the weak layer length the higher the deformation rates at the upper and lower ends of the weak layer are. Weak layers of $a>8 \mathrm{~m}$ are required for all investigated snow densities and snow temperatures in order the achieve the necessary brittle fracture rates.

- The magnitude of the strain-rate concentrations is strongly influenced by temperature and temperature development. For a given temperature rise, slower changes in temperature allow the snowcover to relax and deform, reducing the stress-level and, subsequently, the strain-rates. The highest strain-rates are not 


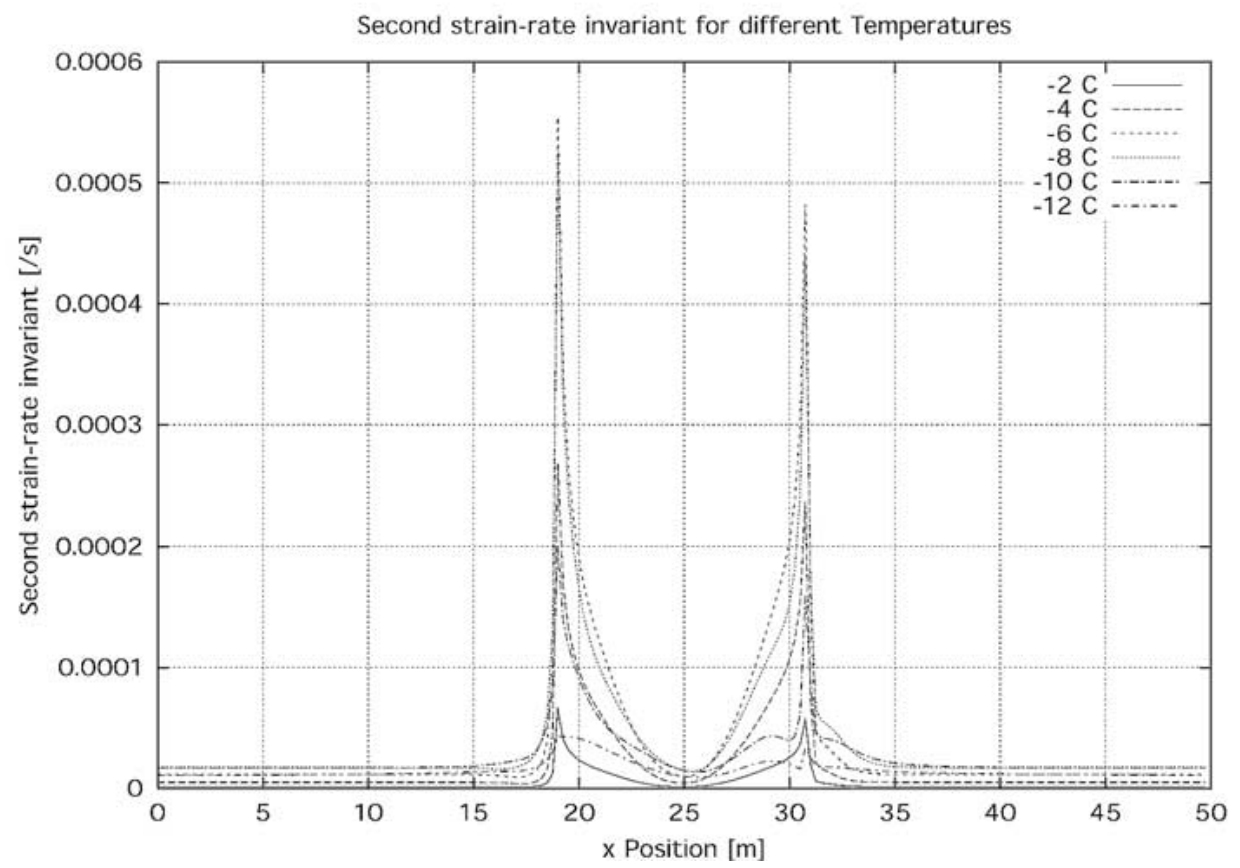

Figure 6. Second strain-rate invariant $\dot{\epsilon}_{I I}$ for different temperatures with a constant upper layer density of $\rho_{1}=180 \mathrm{kgm}^{-3}$ and a weak layer length of $a=12 \mathrm{~m}$.

obtained for the highest temperature, but rather for a temperature around $\mathrm{T} \approx$ $-5^{\circ} \mathrm{C}$.

- The brittle tensile strain-rates are concentrated in a small zone at the upper end of the weak layer. The compressive strain-rates at the lower end are spread over a larger region. Thus, the simulation results show that the initial rupture most likely occurs in the tensile zone, as expected.

In future the thermo-mechanical finite element model presented in this work will be applied to investigate snow avalanche formation in greater detail. For example the conditions for snow fracture as well as snow glide at the ground interface will be introduced into the model.

\section{Acknowledgements}

The authors would like to thank Dr. P. Foehn of the Swiss Federal Institute for Snow and Avalanche Research for his helpful discussions of the simulation results. In addition, the authors thank the C. Scapozza of the Institute of Geotechnical Engineering, Swiss Federal Institute of Technology, Zurich, for his help with the viscoelastic material law. Finally, we thank the Swiss National Science Foundation for the financial support of this work. 


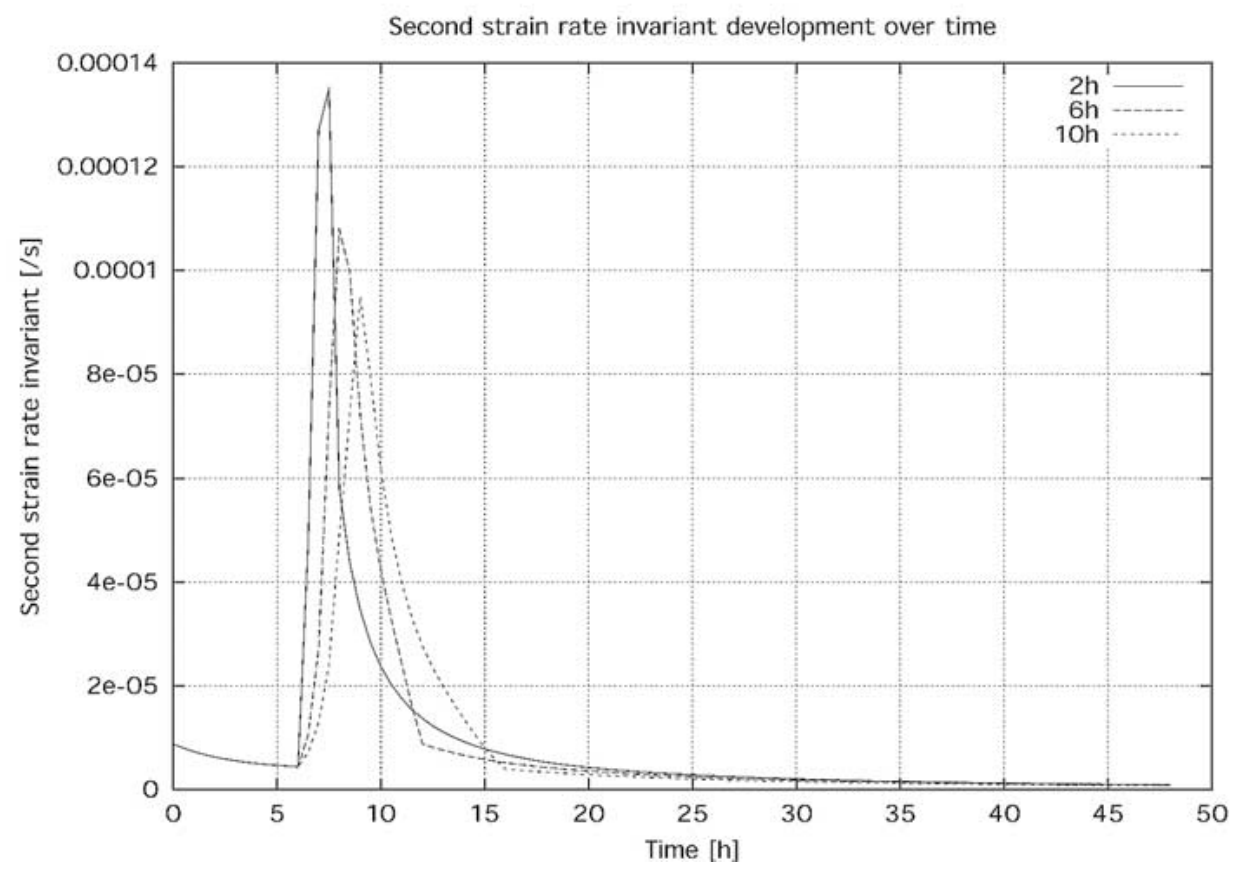

Figure 7. Second strain rate invariant $\dot{\epsilon}_{I I}$ at the upper end of the weak layer. The shorter the time during which the $10{ }^{\circ} \mathrm{C}$ temperature change happens, the higher the peak strain-rates are.

\section{References}

Adams, E. and Sato, A.: 1993, 'Model for Effective Thermal Conductivity of a Dry Snow Cover Composed of Uniform Ice Spheres', Ann. Glaciol. 18, 300-304.

Bader, H. P., Gubler, H. U. and Salm, B.: 1988, 'Distributions of Stresses and Strain-rates in Snowpacks', Proceedings of the Conference: Numerical Methods in Geomechanics, Swoboda, Innsbruck.

Bader, H. P. and Salm, B.: 1990, 'On the Mechanics of Snow Slab Release', Cold Regions Science and Technology. 17, 287-300.

Bartelt, P. and von Moos, M.: 2000, 'Triaxial Tests to Determine a Microstructure-based Snow Viscosity Law', Ann. Glaciol. 31, 457-462.

Beer, G.: 1985, 'An Isoparametric Joint/Interface Element for Finite Element Analysis', International Journal for Numerical Methods in Engineering 21, 585-600.

Bozhinskiy, A. N. and Losev, K. S.: 1998, 'The Fundamentals of Avalanche Science', Swiss Federal Institute for Snow and Avalanche Research, (SFISAR).

Day, R. A. and Potts, D. M.: 1994, 'Zero Thickness Interface Elements - Numerical Stability and Application', International Journal for Numerical and Analytical Methods in Geomechanics 18, 689-708.

Kaviany, M.: 1995, 'Principles of Heat Transfer in Porous Media', Springer.

Mellor, M.: 1974, 'A Review of Basic Snow Mechanics', Proceedings of the Grindelwald Symposium, April 1974, IAHS Publication No. 114.

Munter, W.: 1997, '3 × 3 Lawinen: entscheiden in kritischen Situationen', Pohl \& Schellhammer, cop. Garmisch-Partenkirchen. 220. 
Reddy, J. and Garling, D.: 1994, 'The Finite Element Method in Heat Transfer and Fluid Dynamics', CRC Press.

Petrenko, V. and Whitworth, R.: 1999, 'The Physics of Ice', Oxford University Press.

Salm, B.: 1971, 'On the Rheological Behavior of Snow under High Stresses', Contrib. Inst. Low Temperature Science. Hokkaido Univ., Sapporo, Japan. Ser. A(23), 1-43.

Scapozza, C. and Bartelt, P.: 2003a, 'Triaxial Tests on Snow at Low Strain-rate. Part II: Constitutive Behaviour', J. Glaciol. in press.

Scapozza, C. and Bartelt, P.: 2003b, 'The Influence of Temperature on the Small Strain Viscous Deformation Mechanics of Snow - A Comparison to Polycrystalline Ice', Ann. Glaciol. in press. von Moos, M., Bartelt, P., Zweidler, A., and Bleiker, E.: 2003, 'Triaxial Tests on Snow at Low Strain-rate. Part I: Experimental Device', J. Glaciol. in press.

Voytkovskiy, K. F.: 1977, 'Mekhanicheskiye svoystva snega [Mechanical properties of snow]', C. E. Bartelt (trans.), Moscow, Nauka. Sibirskoye Otdeleniye. Institut Merzlotovedeniya. 